\title{
The Effect of Implementing Some Generative Learning Model Strategies in Teaching Reading Comprehension
}

\author{
Fatima Mahmoud Basaffar \\ English Language Institute, King Abdulaziz University \\ PO BOX 15213 Jeddah 21444, Saudi Arabia \\ Tel: 966-503-617-782Ｅ-mail: fbasfar@kau.edu.sa
}

Received: January 2, 2017 Accepted: January 15, 2017 Published: January 17, 2017

doi:10.5296/ijele.v5i1.10612 URL: http://dx.doi.org/10.5296/ijele.v5i1.10612

\begin{abstract}
The present study investigates the effect of implementing some Generative Learning Model (GLM) strategies in teaching English as a foreign language (EFL) to foundation year students at King Abdulaziz University (KAU). A total of 120 female students studying English at the English Language Institute (ELI) at KAU preparatory year participated in this study. Participants were divided into two groups, a controlled group and an experimental group. Each group consists of 60 students selected randomly. All students were of the same level at the foundation year according to the institute's placement test. A reading comprehension pre-test was conducted for the two groups to assure similarities. The test consists of two parts, multiple choice questions (MCQs) and Generative Learning Model question (GLMQs). Generative Learning Model strategies were implemented in class using reading texts that are part of the institute's curriculum. Students were trained to use some GLM strategies including paraphrasing, generating titles, generating questions, drawing mind-maps and images. Four weeks later, a post-test took place for the experimental as well as for the controlled group. Results indicate a significant improvement in students' performance as far as the GLMQs were considered. Moreover, a positive attitude was strongly reflected in students' behavior inside the classroom. In addition, students were asked to reflect on the technique used. Positive feedback was strongly evident in their writings. The method adopted turned the class into an entirely student-centered class. Dealing with challenging reading texts turned to be an exciting experience for both the learners and the teacher.
\end{abstract}

Keywords: Generative learning model, Learning strategies, Reading comprehension, Teaching approach 


\section{Ml Macrothink}

\section{Introduction}

One of the main areas where students fail to achieve high scores at the ELI at KAU is the reading comprehension part. Students always complain about the reading part of the test to be one of the most challenging tasks. A quick look at results clearly indicates that reading comprehension receives the lowest scores compared to other skills in the computer-based test (CBT) at KAU's preparatory year. Bellow is the percentage of results for a CBT for ten sections selected randomly.

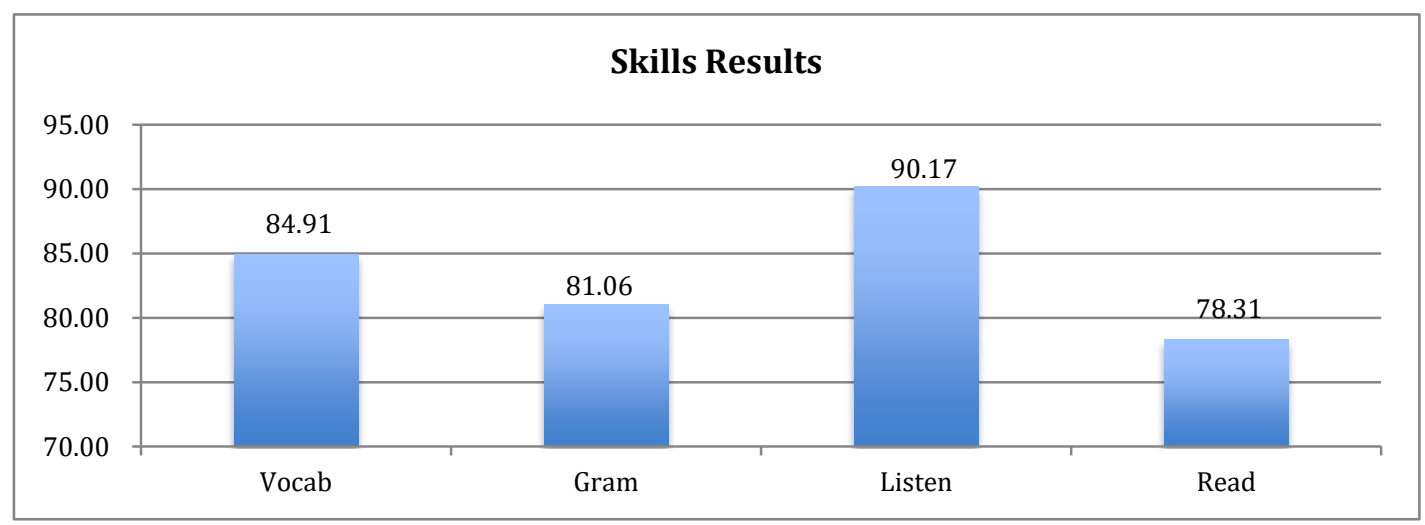

Figure 1. Preparatory year students' results for the four skills

Moreover, instructors find dealing with reading texts in the classroom challenging. The need for the present study emerged not only from the fact that students were achieving low scores in reading comprehension CBTs, but also for the lack of interaction during reading comprehension sessions.

According to Al-Makhzoumi (1986) most teaching techniques of reading focus on teaching the meanings of vocabulary and pronunciation. Little emphasis is given to reading comprehension. These techniques rarely lead the learners to relate new materials presented in class to their previous knowledge nor do they provided learners with opportunities to generate their own ideas (Al-Makhzoumi, 1986).

Wirttrock 1986, stressed the importance of the shift from the emphasis on the effects of external stimuli on the learner to the role of the learner in the learning process (M.C. Wittrock \& Association, 1986). It was during this period that the idea of Generative Learning (GL) emerged. The GLM works basically on changing students' prescriptive of reading comprehension from memorizing information to generating understanding by relating information presented in class to their previous experience and knowledge. Denner, Rickards et al. (2003) detected significant increase in learning from narrative text due to the use of prior knowledge and the simultaneous generative learning effect (Denner, Rickards, \& Albanese, 2003). Al-Zubaidi (1994) and Burns, Hodgson et al. (2004) also reported interchangeable effect between background knowledge and reading comprehension (al-Zubaidi, 1994; Burns, Hodgson, Parker, \& Fremont, 2011). 
The term GLM, first introduced by Osborne \& Wittrock (1985), referrers to a model in which the instructor gives learners a prompt or series of prompts to perform activities that require the active generation of 1) meaningful connections between new information and prior knowledge and 2) meaningful relations amongst newly learned concepts (M.C. Wittrock, 1991). According to Wittrock 1990 \& 1991, it is a teaching approach that combines strategies in an attempt to help students become active and responsible for constructing meaning from class activities by building relations. The model conceptualizes learning as the interplay between four components: motivational processes, learning processes, knowledge creation processes, and generation processes through subject-matter concepts and then between the subject matter and students' existing knowledge (M. Wittrock, Clark, \& Peterson, 1990; M. C. Wittrock, 1991) The theory is basically based on four elements; recall, integration, organization and elaboration.

Meaningful learning according to Wittrock is the result of complex neural processes where learners creates meaningful relations between new and prior knowledge and amongst related concepts. Since drawing this type of connections requires more than just remembering, the application of the GLM helps learners' not only to remember and comprehend but also use newly learned information for application and reasoning (M.C. Wittrock, 1992). The generative process, as conceived by Wittrock (1991) and Wittrock and Alesandrini (1990) is to construct two types of relations: among the parts of the text presented (e.g., learners should compose new words, sentences, paragraphs and large units of the reading passage), and between the learners' knowledge and experience. Each type of relations requires different types of learning and teaching strategies. The first type is to help learners understand how items are related to each other in the text thorough generating titles, headings, questions, objectives, summaries, graphs, tables, and concept maps. The second type of the generative model focuses on integrating relationships between external stimuli and the learners' memory through creating metaphors and analogies, paraphrasing, creating examples, drawing pictures or inferences (Ritchie \& Volkl, 2000; M. C. Wittrock, 1991, 1992). The instructor's role is to help learners draw relations and generate meaningful connections. Accordingly, reading comprehension depends on what learners generate and do during instructions.

The present study aims at investigating the effect of implementing some GLM strategies in teaching English as a foreign language to foundation year students at KAU. Several strategies, following the recall stage, were implemented such as generating titles, paraphrasing, generating questions and drawing mind-maps and images. Students were trained to use these strategies for four weeks and a post-test took place by the end of that period.

\section{Literature Review}

Research on generative learning began with a focus on learning from text focusing on comprehension and recall, see for example, (Doctorow, Wittrock, \& Marks, 1978; Hooper, Sales, \& Rysavy, 1994; Linden \& Wittrock, 1981; M. C. Wittrock \& Alesandrini, 1990).

Linden and Wittrock (1981) conducted a study focusing on some GLM strategies. The study shows that the group experiencing the GLM strategies comprehended more with a positive correlation between the number of text-related generations of metaphors, summaries, and/or 
illustrations and their performance on the comprehension test (Linden \& Wittrock, 1981). Moreover, in 1990, Wittrock and Alesandrini conducted another study. They found that the summary-generating and analogy-generating groups in their study performed better than the read-only group on the objective test (M. C. Wittrock \& Alesandrini, 1990).

A number of researchers have tested the viability of Wittrock's model by investigating different generative strategies (e.g., note taking, summarizing, questioning, organizational strategies, concept mapping, creation of analogies) with college-level students performing primarily recall, comprehension, and identification tasks (Burton, Niles, Lalik, \& Reed, 1986; Sutliff, 1986). Findings positively supported the use of generative strategies in the recall, retention, and comprehension of facts. Results indicate that the implementation of the GLM in the classroom enhanced learner ability to recall and comprehend new knowledge.

Other results such as (Al-Qatawneh, 2010; Davis \& Hult, 1997; Hooper et al., 1994; Kourilsky, Esfandiari, \& Wittrock, 1996; Ritchie \& Volkl, 2000) supported the findings that using generative instructional strategies in teaching reading comprehension positively affected reading comprehension, vocabulary recall, retention, and decoding.

Al-Qatawneh \& Alodwan (2010) examined the effect of using the GLM in enhancing reading comprehension skills and stimulating strategy awareness in English of the Jordanian secondary school students. The study involved two measures, a reading comprehension test and a reading strategy awareness questionnaire. Results showed that there was a statistically significant difference between the mean scores of the two groups on the reading comprehension test and on the strategy awareness questionnaire. The study highly recommended providing additional knowledge dealing with learners of different levels (Al-Qatawneh, 2010).

The present study investigates the effect of implementing some GLM strategies in teaching reading comprehension to foundation year students at the English Language Institute at King Abdulaziz University. The purpose behind the study is to test the effect of using these strategies in increasing students' comprehension level in dealing with challenging texts in this context.

The present study aims at answering the following question:

1. Does the implementation of some of GLM strategies positively affect students' reading comprehension level in the Eli at KAU?

In order to investigate this question, the following hypothesis was developed:

H1: Students exposed to the GLM strategies (i.e. generating titles, generating questions, paraphrasing, drawing images and concept maps) at the foundation year at KAU in reading tasks will exhibit a higher level of comprehension and perform better on the comprehension tests than students who are not exposed to the GLM strategies (i.e. following the conventional way of teaching, reading silently, checking unfamiliar words, discussing parts of the text and answering related questions). 


\section{Method}

\subsection{Participants}

A total of 120 female students participated in this study. All students were of the same level at the foundation year according to KAU's placement test. Participants were divided into two groups, a controlled group and an experimental group. Each group consists of 60 students from two different sections selected randomly. In order the check similarity, a pre-test was conducted on the two groups. Results indicate no significant difference between the two groups at this stage.

\subsection{Research Instrument}

A test was prepared to be used as the research tool. In order to check the reliability and validity of the tool, a pilot study was first conducted on a group of 30 students of the same level. The reading comprehension test was modified accordingly.

The test consists of two parts, multiple choice questions (MCQs) and GLM questions (GLMQs). The two groups were taught for four weeks the same material assigned as part of the curriculum for this level by the institute. The experimental group was trained to use the GLM strategies mentioned above. The same texts were introduced to the controlled group using a more conventional method, i.e. reading silently, checking unfamiliar words, discussing parts of the text and answering related questions. Four weeks later, a post-test took place for both the experimental and the controlled group.

\subsection{Procedure}

GLM strategies were introduced to the experimental group. Learners were exposed to these strategies for four weeks. Each session started with a recall stage. During this stage, students were introduced to the topic by presenting them with some related photos/videos. Students were then encouraged to answer questions related to the topic, connect it to their previous knowledge, and relate the topic to things directly related to their own world/life. They were encouraged to discuss, share ideas, debate and answer related questions. At this stage, students were given the chance to do a quick search on the Internet to find some related information/answers to the questions. They were then encouraged to present in front of the class what they have found in relation to the topic. The purpose behind this warming up activity was to engage students and raise their interest in the text, relate it to their own life, and help them connect previous to present knowledge.

Students were then asked to skim the whole text within a limited time; no dictionaries were to be used at this stage. Students were asked to try to find the main idea from the text individually. The following stage was to seat students in groups. Each group consists of 4-5 students. Each group was assigned part of the text to discuss within their group. Each member in the group had a task to present to the whole class. Tasks included explaining vocabulary, paraphrasing, generating titles, generating questions, and drawing mind-maps and pictures. Students were asked to use drawings and examples to explain the vocabulary, paraphrase the assigned part in two to three sentences depending on the length of the text, be 
prepared to answer any questions related to their part, generate two to three questions and generate a new title for the text or the part of the text assigned. Some techniques were used such as voting for the best presentation to encourage students to participate.

\section{Results}

Only 62 students out of the 120 participants selected to participate in this study completed the two tests. Some students were absent on the day of taking the post-test. Others were excluded for failing to complete the test. All scores were inserted and analyzed using the independent and paired-sample T-tests. The following tables present the results for the two groups in each test.

Table 1. Pre-test results for the experimental and controlled groups for the two parts of the test

\begin{tabular}{ccccc}
\hline Group & Mean & Std. Deviation & Sig. (2-tailed) & Std. Error Mean \\
\hline Exp. & 11.6774 & 3.52503 & .574 & .63311 \\
\hline Cont. & 11.0667 & 4.82760 & .576 & .88140 \\
\hline
\end{tabular}

Table 1 shows the results for the pre-test run on both the experimental and controlled group. This step was important to check similarity between the two groups. Results indicate no significant difference between the two groups at this stage.

Four weeks later, the two groups took the same test again. The controlled group as well as the experimental group were exposed to the material assigned by the institute including reading comprehension texts along with other language skills. Only the experimental group was subject to the GLM strategies while teaching. Overall results indicate a significant difference between the two groups. The experimental group's results increased significantly but there was no significant difference in the controlled group's results. The following table shows the exact results.

Table 2. Post-test results for the experimental and controlled groups for the two parts of the test

\begin{tabular}{rcrcc}
\hline Group & Mean & Std. Deviation & Sig. (2-tailed) & Std. Error Mean \\
\hline Exp. & 14.5484 & 3.61330 & .002 & .64897 \\
\hline Cont. & 11.1290 & 4.82177 & .003 & .86602 \\
\hline
\end{tabular}

However, a deeper look into results indicates that the increase in the experimental group's results was mainly affected by the participant's performance in the part related to GLMQs in the test. As far as the MCQs part was considered, a very slight improvement was noticed between the two groups in the mean.

The same group's results were also analyzed using the paired sample T-test. 
Table 3. Pre and Post-test results for the controlled group for the GLMQs part of the test

\begin{tabular}{ccccc}
\hline & Mean & Std. Deviation & Sig. & Std. Error Mean \\
\hline Cont.PreGL & 5.4516 & 3.16058 & & .56766 \\
\hline Cont.PostGL & 5.5484 & 3.72235 & .828 & .66855 \\
\hline
\end{tabular}

Table 4. Pre and Post-test results for the controlled group for the MCQs part of the test

\begin{tabular}{ccccc}
\hline & Mean & Std. Deviation & Sig. & Std. Error Mean \\
\hline Cont.PreMC & 5.7419 & 2.27988 & & .40948 \\
\hline Cont.PostMC & 5.5806 & 2.30614 & .644 & .41419 \\
\hline
\end{tabular}

As mentioned above, no significant difference was found as far as the controlled group results were concerned.

Table 5. Pre and Post-test results for the experimental group for the GLMQs part of the test

\begin{tabular}{rcccc}
\hline & Mean & Std. Deviation & Sig. (2-tailed) & Std. Error Mean \\
\hline Exp.PreGL & 6.1290 & 3.13839 & & .56367 \\
\hline Exp.PostGL & 8.2581 & 3.26566 & .004 & .58653 \\
\hline
\end{tabular}

Table 6. Pre and Post-test results for the experimental group for the MCQs part of the test

\begin{tabular}{ccccc}
\hline & Mean & Std. Deviation & Sig. (2-tailed) & Std. Error Mean \\
\hline Exp.PreMC & 5.5484 & 2.11090 & & .37913 \\
\hline Exp.PostMC & 6.2903 & 2.08476 & .120 & .37443 \\
\hline
\end{tabular}

As can be seen from the tables presented above, significant results were achieved by the experimental group in the GLMQs' part. A slight increase was found in the MCQs' part.

\section{Discussion}

Results indicate an overall increase in the experimental group's performance in dealing with the same reading comprehension test but not in the controlled group's performance. The figure bellow shows the overall progress for the two groups in the two tests. 


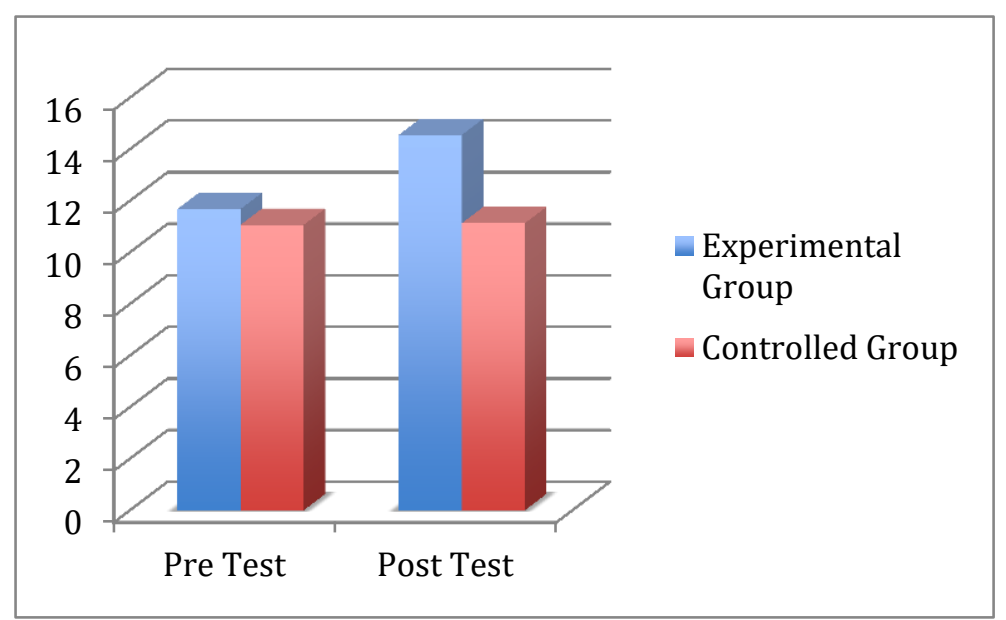

Figure 2. Overall Results for the Two Groups

Although there was a significant increase in results as far as the experimental group is concerned, the increase was mainly caused by their achievement in the part related to the GLMQs rather than in the MCQs' part. The figures below indicate the progress achieved by the two groups for each part of the test.

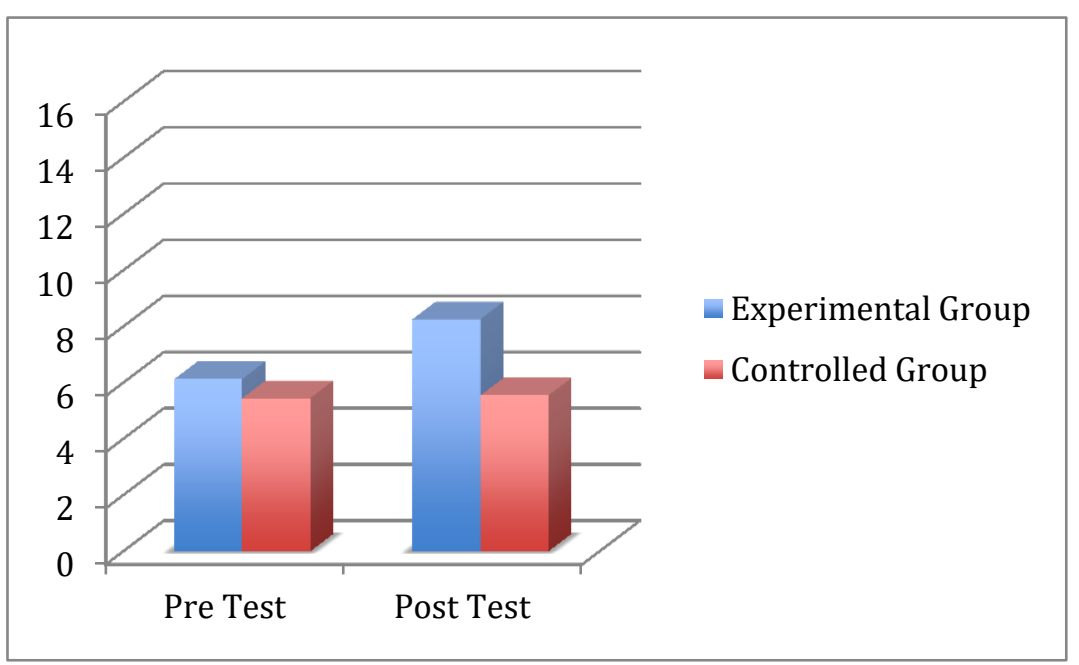

Figure 3. GLMQs Results for the Two Groups 


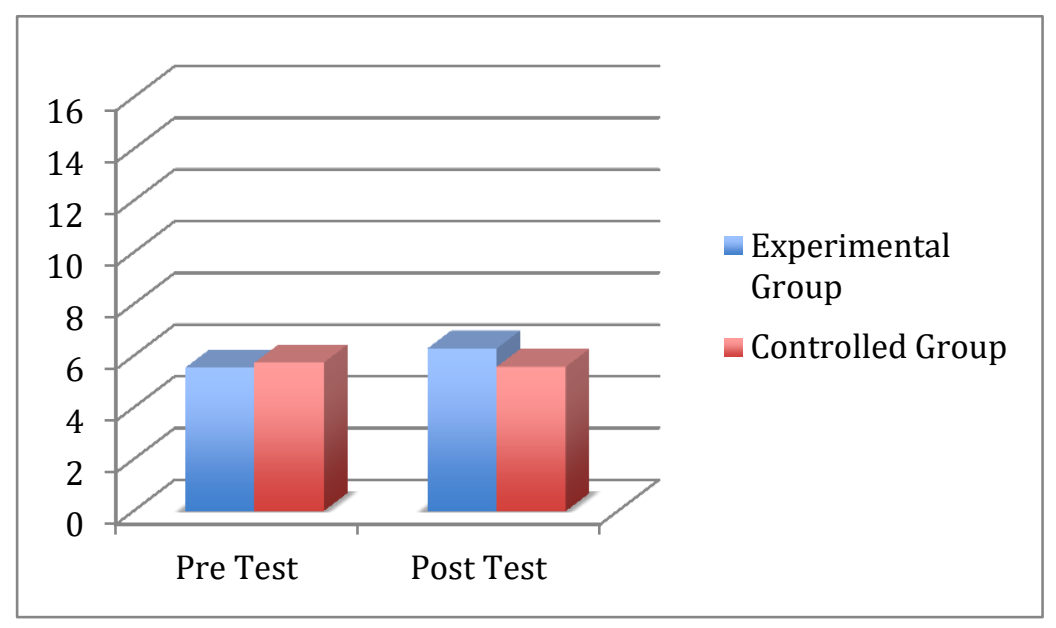

Figure 4. MCQs Results for the Two Groups

This increase in the GLMQs can obviously be explained in light of the training the learners received on GLM strategies. Although the method didn't prove to significantly improve students' comprehension level in dealing with MCQs, it was effective in many other ways. Students were able to paraphrase texts, generate titles, generate questions, express themselves through mind mapping and drawing which are some of the crucial skills language learners need. Moreover, being exposed to these skills, led to a great improvement in learners' confidence and their overall performance in the classroom. In addition, the method created a student-centered class where students were working in groups all the time to complete the tasks assigned to them. Feedback received from students about the method adopted was positive. They enjoyed dealing with challenging texts.

\section{Conclusion}

The present study investigated the implementation of some GLM strategies in reading comprehension on female students in the preparatory year at the English Language Institute at King Abdulaziz University. A random sample of 120 students participated in this study. All students undertook a reading comprehension test consisting of two parts, objective questions and MCQs. Students were divided into two groups, a controlled group and an experimental group. Students were exposed to reading comprehension texts that are part of the ELI curriculum. The controlled group dealt with the texts in the conventional way of skimming, scanning, checking vocabulary and answering related questions. The experimental group was trained to use some GLM strategies such as paraphrasing, generating titles, generating questions and drawing mind-maps and images. Four weeks later, a post-test took place for the controlled as well as for the experimental group. Results indicate significant difference in the learners' performance as far as GLMQs are considered. A slight, yet not statistically significant, increase was found in the MCQs' part. However, a positive attitude was strongly reflected in students' interaction during the reading comprehension tasks in the classroom. Moreover, students were asked to provide a written feedback regarding the strategy adopted. A positive feedback was strongly present and learners expressed their enjoyment in dealing with the reading texts. Learners found themselves active all the time and enjoyed the 
creativity in paraphrasing the text, generating titles and questions and coming up with mind-maps and drawings related to the text. Results obtained support results found in other studies.

\section{Limitations and Recommendations for Further Studies}

The present study focused on preparatory year students at KAU of one level. The same study can be replicated on different groups of different levels. The duration of the study was four weeks only due to the quarter system implemented at the institute. It is expected that more sessions and more training can yield more significant results. Training sessions and workshops directed to instructors at the institute and outside the institute are recommended for better performance in dealing with reading comprehension.

\section{Acknowledgement}

I am grateful to all the English language institute members at King Abdulaziz University for their help and support. My contribution to the field would have never been possible without their presence. A special thank you goes to the best model Dr. Dawla Alamri, the source of inspiration Dr. Nesreen Subahi and my beloved colleague Dr. Manal Qutob. I would also like to thank my wonderful students for taking part in this study. Last and foremost, there are no words to express my gratitude to my great parents, my supporting husband and my lovely kids whose love and support has always filled my life towards success.

\section{References}

Al-Makhzoumi, K. (1986). Teaching reading comprehension to secondary students in Jordan. Dirasat, 13(6).

Al-Qatawneh, Khalil S. (2010). The effect of the reciprocal teaching method on enhancing critical reading to skills of Jordanian secondary school student. European Journal of Social Sciences, 34(1). Retrieved from http://proxy1.ncu.edu/login?url=http://search.ebscohost.com/login.aspx?direct=true \&db=edb $\& \mathrm{AN}=109133140 \&$ site $=$ eds-live

al-Zubaidi, Zain-ud-Din. (1994). Summarized Sahih al-Bukhari: Riyadh: Maktaba Dar-us-Salam.

Burns, Matthew K, Hodgson, Jennifer, Parker, David C., \& Fremont, Kathryn. (2011). Comparison of the effectiveness and efficiency of text previewing and preteaching keywords as small-group reading comprehension strategies with middle-school students. Literacy Research and Instruction, 50(3), 241-252. Retrieved from http://proxy1.ncu.edu/login?url=http://search.ebscohost.com/login.aspx?direct=true \&db=edb $\& \mathrm{AN}=61158210 \&$ site $=$ eds-live

Burton, John K, Niles, Jerome A, Lalik, Rosary M, \& Reed, W Michael. (1986). Cognitive 
capacity engagement during and following interspersed mathemagenic questions. Journal of Educational Psychology, $78(2)$ 147. http://dx.doi.org/proxy1.ncu.edu/10.1037/0022-0663.78.2.147

Davis, Martha, \& Hult, Richard E. (1997). Effects of writing summaries as a generative learning activity during note taking. Teaching of Psychology, 24(1), 47-50. Retrieved from:http://proxy1.ncu.edu/login?url=http://search.ebscohost.com/login.aspx?direct=true\&db $=$ eric $\& A N=E J 548221 \&$ site $=$ eds-live

Denner, Peter R, Rickards, John P, \& Albanese, Andrew J. (2003). The effect of story impressions preview on learning from narrative text. The Journal of experimental education, 71(4), 313-332. http://dx.doi.org/10.1080/00220970309602068

Doctorow, Marleen, Wittrock, Merlin C, \& Marks, Carolyn. (1978). Generative processes in reading comprehension. Journal of Educational Psychology, 70(2), 109.

Hooper, Simon, Sales, Gregory, \& Rysavy, S Del Marie. (1994). Generating summaries and analogies alone and in pairs. Contemporary Educational Psychology, 19(1), 53-62. http://dx.doi.org/10.1006/ceps.1994.1006

Kourilsky, Marilyn, Esfandiari, Mahtash, \& Wittrock, Merlin C. (1996). Generative teaching and personality characteristics of student teachers. Teaching and Teacher Education, 12(4), 355-363. http://dx.doi.org/10.1016/0742-051X(95)00045-L

Linden, Michele, \& Wittrock, Merlin C. (1981). The teaching of reading comprehension according to the model of generative learning. Reading Research Quarterly, 44-57. Retrieved from http://proxy1.ncu.edu/login?url=http://search.ebscohost.com/login.aspx?direct=true\&db $=$ edb \&AN=19173960\&site=eds-live

Ritchie, Donn, \& Volkl, Chris. (2000). Effectiveness of two generative learning strategies in the science classroom. School Science and Mathematics, 100(2), 83-89. http://dx.doi.org/10.1111/j.1949-8594.2000.tb17240.x

Sutliff, Ronald I. (1986). Effect of adjunct postquestions on achievement. Journal of Industrial Teacher Education, 23(3), 45-54. Retrieved from http://proxy1.ncu.edu/login?url=http://search.ebscohost.com/login.aspx?direct=true \&db=eric $\& \mathrm{AN}=\mathrm{EJ} 333897 \&$ site $=$ eds-live

Wittrock, MC, Clark, CM, \& Peterson, PL. (1990). Vol. 3: Students' thought processes: New York [etc.]: MacMillan [etc.].

Wittrock, Merlin C. (1991). Generative teaching of comprehension. The Elementary School Journal, 169-184.

Wittrock, Merlin C. (1992). Generative learning processes of the brain. Educational Psychologist, 27(4), 531-541.

Wittrock, Merlin C, \& Alesandrini, Kathryn. (1990). Generation of summaries and analogies and analytic and holistic abilities. American Educational Research Journal, 27(3), 489-502. 
Retrieved from http://proxy1.ncu.edu/login?url=http://search.ebscohost.com/login.aspx? direct $=$ true $\& \mathrm{db}=\mathrm{edb} \& \mathrm{AN}=19603824 \&$ site=eds-live

Wittrock, Merlin C, \& Association, American Educational Research. (1986). Handbook of research on teaching: a project of the American Educational Research Association: Macmillan; Collier-Macmillan. Retrieved from http://proxy1.ncu.edu/login?url=http://search.ebscohost.com/login.aspx?direct=true $\& d b=e d s b$ vb\&AN=EDSBVB.BV009134895\&site=eds-live

\section{Copyright Disclaimer}

Copyright for this article is retained by the author(s), with first publication rights granted to the journal.

This is an open-access article distributed under the terms and conditions of the Creative Commons Attribution license (http://creativecommons.org/licenses/by/3.0/). 